\title{
Adverse renal effects of anaplastic lymphoma kinase inhibitors and the response to alectinib of an ALK+ lung cancer patient with renal dysfunction
}

This article was published in the following Dove Press journal:

OncoTargets and Therapy

29 June 2017

Number of times this article has been viewed

\author{
Midori Shimada ${ }^{1,2}$ \\ Minoru Fukuda ${ }^{2,3}$ \\ Masaaki Fukuda ${ }^{2}$ \\ Takeshi Kitazaki \\ Kohji Hashiguchi² \\ Takaya Ikeda' \\ Hiroyuki Yamaguchi' \\ Katsumi Nakatomi' \\ Kazuto Ashizawa ${ }^{3}$ \\ Hiroshi Mukae' \\ 'Department of Respiratory Medicine, \\ Unit of Translational Medicine, \\ Nagasaki University Graduate School \\ of Biomedical Sciences, ${ }^{2}$ Department \\ of Respiratory Medicine, Japanese Red \\ Cross Nagasaki Genbaku Hospital, \\ ${ }^{3}$ Clinical Oncology Center, Nagasaki \\ University Hospital, Nagasaki, Japan
}

Correspondence: Minoru Fukuda Clinical Oncology Center, Nagasaki University Hospital, I-7-I Sakamoto, Nagasaki 852-850I, Japan

$\mathrm{Tel}+8 \mid 958197779$

Fax +8I 958197776

Email mifukuda258@nifty.com

\begin{abstract}
A 62-year-old female patient with renal dysfunction and pulmonary adenocarcinoma developed postoperative recurrence and received carboplatin/pemetrexed and maintenance pemetrexed. As an anaplastic lymphoma kinase (ALK) gene translocation was identified, the therapy was changed to crizotinib. However, the patient's blood creatinine level increased, and her physical status worsened. Alectinib also induced exacerbation of renal dysfunction but was controlled by dose reduction of $140 \mathrm{mg}$ twice daily for 2 weeks treatment and 2 weeks break were repeated, and exhibited a partial response for 16 months. Here, we describe the case in which alectinib treatment had beneficial clinical effects on ALK-positive lung adenocarcinoma, which controlled the adverse renal effects by dose reduction and drug breaks.
\end{abstract}

Keywords: lung cancer, ALK, renal dysfunction, alectinib

\section{Introduction}

Anaplastic lymphoma kinase (ALK) rearrangements are seen in 3\%-7\% cases of nonsmall cell lung cancer (NSCLC), predominantly in cases involving adenocarcinoma histology and light or nonsmoking young individuals. ${ }^{1-3}$ Alectinib is a highly potent, oral, selective, second-generation ALK tyrosine kinase inhibitor targeting the ALK receptor, and it has been shown to exhibit marked activity against ALK-positive NSCLC. ${ }^{4,5}$ The treatment-related adverse events of alectinib are generally mild, but significant increases in blood creatinine levels have been detected. ${ }^{4}$ Here, we present a case in which alectinib produced a clinical response in a patient with ALK-positive NSCLC who exhibited renal dysfunction. We also describe how the adverse renal effects of the drug were overcome. Written informed consent was obtained from the patient to publish the report and accompanying images.

\section{Case presentation}

A 62-year-old female patient came to our hospital after being referred from a local hospital due to chest X-ray abnormalities in the left upper lung field. Her medical history included glomerulonephritis and nephrotic syndrome. The patient had been diagnosed with pulmonary adenocarcinoma 4 years ago and underwent left upper lobectomy (pT2aN1M0, stage IIA). Two years ago, a chest X-ray and a CT scan revealed multiple nodules in the left lower pulmonary lobe, resulting in a diagnosis of recurrent lung cancer. The patient had an Eastern Cooperative Oncology Group performance status (PS) of 0 and received 3 cycles of carboplatin and pemetrexed chemotherapy. Because 1) we usually selected cisplatin and pemetrexed for young lung cancer patients with 
adenocarcinoma without epidermal growth factor receptor (EGFR) sensitive mutations, 2) the patient had renal dysfunction, 3) although cytotoxic agents including both carboplatin and pemetrexed may induce renal adverse effects, its renal toxicities were inferior to cisplatin, therefore, we selected the regimen of carboplatin and pemetrexed. The patient was carefully treated and renal dysfunction did not progress. As the tumor response, according to the response evaluation criteria in solid tumors guidelines, was classified as stable disease, the patient subsequently received maintenance chemotherapy involving 6 cycles of pemetrexed. Simultaneously, the genes encoding the EGFR and ALK were analyzed using tumor tissue, which was removed during the previous operation. As an ALK gene translocation was identified using fluorescence in situ hybridization, in addition, developed to progressive disease (PD), the patient's treatment was changed to crizotinib monotherapy. Laboratory analysis revealed the following findings: a leukocyte count of $5,300 / \mu \mathrm{L}$, a lactate dehydrogenase level of 314 IU/L, a blood urea nitrogen level of $36.7 \mathrm{mg} / \mathrm{dL}$, a serum creatinine level of $2.96 \mathrm{mg} / \mathrm{dL}$, and positivity for albuminuria. These laboratory findings were indicative of renal dysfunction. Tumor marker tests revealed an elevated cytokeratin 19 fragment level $(5.6 \mathrm{ng} / \mathrm{mL})$. We did not have enough knowledge and experience about renal adverse effects of crizotinib, it was administered orally at a dose of $250 \mathrm{mg}$ twice daily without dose reduction. During the 6 days of crizotinib treatment, the patient's serum creatinine levels increased to $4.10 \mathrm{mg} / \mathrm{dL}$, and her physical status worsened to a PS of 2 . Thus, crizotinib was discontinued, and the patient's serum creatinine levels decreased to $2.54 \mathrm{mg} /$ $\mathrm{dL}$ after 3 weeks. Alectinib was then administered orally at a dose of $140 \mathrm{mg}$ twice daily because of renal dysfunction. During the 15 days of alectinib treatment, the patient's serum creatinine levels increased to $3.72 \mathrm{mg} / \mathrm{dL}$. Then, alectinib was discontinued, and the patient's serum creatinine levels decreased to $2.78 \mathrm{mg} / \mathrm{dL}$ within 2 weeks. A timeline of the patient's blood creatinine levels is shown in Figure 1. Oral alectinib was then reintroduced at a dose of $140 \mathrm{mg}$ twice daily for 2 weeks of a 4-week cycle. The patient was treated with two cycles of alectinib and exhibited a partial response (Figures $2 \mathrm{~A}$ and $\mathrm{B}$ and $3 \mathrm{~A}$ and $\mathrm{B}$ ). Alectinib was continued for 16 months in the same manner until PD without severe renal dysfunction and kept serum creatinine near to $2.5 \mathrm{mg} / \mathrm{dL}$. Then the patient was treated by rechallenge crizotinib for 1 month until PD, nivolumab for 5 months until PD, and finally docetaxel for 6 cycles and remained in stable disease with no severe renal dysfunction.

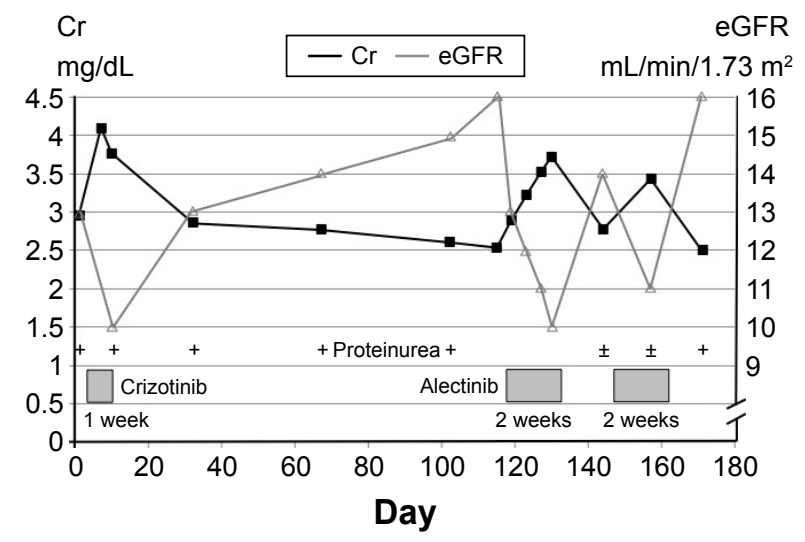

Figure I Timeline of the patient's renal function. Abbreviation: eGFR, estimate glomerular filtration rate.

\section{Discussion}

Crizotinib is an orally administered potent inhibitor of several different oncogenic kinases, including ALK, ROS1, and mesenchymal-epithelial transition, ${ }^{6-8}$ and is widely used to treat ALK-positive NSCLC (mainly adenocarcinoma, rarely squamous cell carcinoma)..$^{9,10}$ Crizotinib is predominantly eliminated in feces $(63 \%)$; however, some is eliminated in urine $(22 \%)$, and both acute and chronic kidney dysfunction have been reported after crizotinib treatment. ${ }^{1-14}$ Camidge et al reported a case of induced acute kidney dysfunction after the treatment of crizotinib. ${ }^{14}$ After 15 days therapy of crizotinib, there was a $26 \%(2.09-2.64 \mathrm{mg} / \mathrm{dL})$ rise in serum creatinine and a $24 \%\left(34-26 \mathrm{~mL} / \mathrm{min} / 1.73 \mathrm{~m}^{2}\right)$ drop in estimated glomerular filtration rate, however, did not show any evidence of acute tubular necrosis (ie, granular casts or renal tubular epithelial cells). Brosnan et al published a retrospective series of 38 stage IV cases of crizotinib-treated NSCLC and reported that the patients' mean estimated glomerular filtration rate decreased by $23.9 \%$ over the first 12 weeks of crizotinib
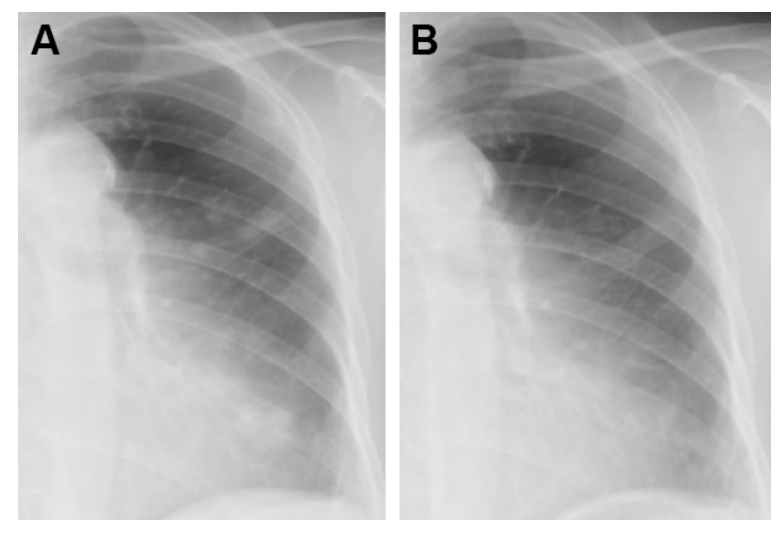

Figure 2 Chest $X$-rays obtained $(\mathbf{A})$ before and $(\mathbf{B})$ after alectinib therapy. 

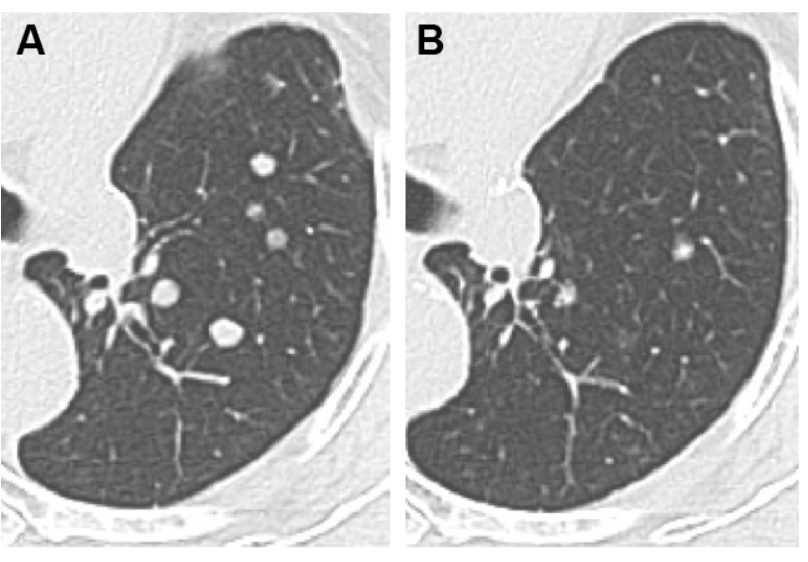

Figure 3 Chest computed tomography scans obtained (A) before and (B) after alectinib therapy.

therapy. ${ }^{15}$ The current formal recommendations for crizotinib therapy state that the dosage should not be adjusted in patients with mild (creatine clearance rate [CRcl]: $60-89 \mathrm{~mL} / \mathrm{min}$ ) or moderate (CRcl: 30-59 $\mathrm{mL} / \mathrm{min}$ ) renal dysfunction, but the dosage should be reduced to $250 \mathrm{mg}$ once a day in patients with severe renal dysfunction (CRcl: $<30 \mathrm{~mL} / \mathrm{min}$ ) who do not require dialysis. ${ }^{11}$ If the dose of crizotinib is not reduced in patients with severe renal dysfunction it can lead to elevated blood creatinine levels, the discontinuation of therapy, and tumor progression. Because most tumors acquire resistance to crizotinib (via various mechanisms), ${ }^{16-18}$ next generation ALK inhibitors are developing.

Alectinib is a second-generation, highly selective, oral ALK inhibitor that exhibited marked activity against ALKpositive NSCLC in clinical studies. ${ }^{4,5}$ Alectinib achieved an outstanding response rate of $93.5 \%(n=46)$ as a first-line therapy for ALK-positive $\mathrm{NSCLC}^{4}$ and a response rate of $48 \%(\mathrm{n}=69)$ as a second-line therapy for ALK-positive crizotinib-resistant NSCLC. ${ }^{5}$ In the former study, 12 of 46 (26\%) patients experienced treatment-related increases in their blood creatinine levels. However, few studies have examined renal dysfunction that occurs as an adverse effect of alectinib therapy, and to the best of our knowledge the current report is the first to describe the clinical course of renal dysfunction during alectinib therapy. In a review article of the renal effects of ALK inhibitors, crizotinib was found to be associated with renal failure, renal cysts, and peripheral edema; however, the effects of alectinib were not described. ${ }^{19}$ Our case demonstrates that both alectinib and crizotinib adversely affect renal function, although alectinib can be used to achieve tumor shrinkage in patients with ALK-positive NSCLC who exhibit renal dysfunction via dose reduction and drug breaks.
We administered $140 \mathrm{mg}$ alectinib twice daily for 2 weeks of a 4-week cycle. Alectinib is normally administered at a dose of $300 \mathrm{mg}$ twice daily on a continuous basis; therefore, we only administered $23 \%$ of the normal dose of alectinib to our patient. Thus, reduced dosing and treatment breaks might overcome the adverse renal effects of ALK inhibitors and provide clinical benefits for patients who are treated with these drugs.

\section{Disclosure}

The authors report no conflicts of interest in this work.

\section{References}

1. Soda M, Choi YL, Enomoto M, et al. Identification of the transforming EML4-ALK fusion gene in non-small-cell lung cancer. Nature. 2007;448(7153):561-566.

2. Shaw AT, Yeap BY, Mino-Kenudson M, et al. Clinical features and outcome of patients with non-small-cell lung cancer who harbor EML4ALK. J Clin Oncol. 2009;27(26):4247-4253.

3. Sasaki T, Rodig SJ, Chirieac LR, Janne PA. The biology and treatment of EML4-ALK non-small cell lung cancer. Eur J Cancer. 2010;46(10):1773-1780.

4. Seto T, Kiura K, Nishio M, et al. CH5424802 (RO5424802) for patients with ALK-rearranged advanced non-small-cell lung cancer (AF-001JP study): a single-arm, open-label, phase 1-2 study. Lancet Oncol. 2013;14(7):590-598.

5. Shaw AT, Gandhi L, Godgeel S, et al. Alectinib in ALK-positive, crizotinib-resistant, non-small-cell lung cancer: a single-group, multicenter, phase 2 trial. Lancet Oncol. 2016;17(2):234-242.

6. Camidge DR, Bang YJ, Kwak E, et al. Activity and safety of crizotinib in patients with ALK-positive non-small-cell lung cancer: updated results from a phase I study. Lancet Oncol. 2012;13(10):1011-1019.

7. Christensen JG, Zou HY, Arango ME, et al. Cytoreductive antitumor activity of PF-2341066 a novel inhibitor of anaplastic lymphoma kinase and c-MET, in experimental models of anaplastic large-cell lymphoma. Mol Cancer Ther. 2007;6(12 Pt 1):3314-3322.

8. Zou HY, Li Q, Lee JH, et al. An orally available small-molecule inhibitor of c-MET, PF-2341066, exhibits cyroreductive antitumor efficacy through antiproliferative and antiangiogenic mechanisms. Cancer Res. 2007;67(9):4408-4417.

9. Gadgeel SM, Bepler G. Crizotinib: an anaplastic lymphoma kinase inhibitor. Future Oncol. 2011;7(8):947-953.

10. Wang W, Song Z, Zhang Y. Response to crizotinib in a squamous cell lung carcinoma patient harbouring echinoderm microtubule-associated protein-like 4-anaplastic lymphoma translocation: A case report. Thorac Cancer. 2016;7(3):355-357.

11. US Food and Drug Administration. Approval History XALKORI, NDA no. 202570. Available from: http://labeling.pfizer.com/showlabeling. aspx?id=676. Accessed November 15, 2013.

12. Gastaud L, Ambrosetti D, Otto J, et al. Acute kidney injury following crizotinib administration for non-small-cell lung carcinoma. Lung Cancer. 2013;82(2):362-364.

13. Martin Martorell P, Huerta Alvaro M, Solis Salguero MA, et al. Crizotinib and renal insufficiency: a case report and review of the literature. Lung Cancer. 2014;84(3):310-313.

14. Camidge DR, Brosnan EM, DeSilva C, et al. Crizotinib effects on creatinine and non-creatinine-based measures of glomerular filtration rate. J Thorac Oncol. 2014;9(11):1634-1637.

15. Brosnan EM, Weickhardt AJ, Lu X, et al. Drug-induced reduction in estimated glomerular filtration rate in patients with ALK-positive non-small-cell lung cancer treated with the ALK inhibitor crizotinib. Cancer. 2014;120(5):664-674. 
16. Doebele RC, Pilling AB, Aisner DL, et al. Mechanisms of resistance to crizotinib in patients with ALK gene rearranged non-small cell lung cancer. Clin Cancer Res. 2012;18(5):1472-1482.

17. Choi YL, Soda M, Yamashita Y, et al. EML4-ALK mutations in lung cancer that confer resistance to ALK inhibitors. $N$ Engl J Med. 2010;363(18):1734-1739.
18. Taniguchi H, Takeuchi S, Fukuda K, et al. Amphiregulin triggered epidermal growth factor receptor activation confers in vivo crizotinibresistance of EML4-ALK lung cancer and circumvention by epidermal growth factor receptor inhibitors. Cancer Sci. 2017;108(1):53-60.

19. Izzedine H, El-Fekih RK, Perazella MA. The renal effects of ALK inhibitors. Invest New Drugs. 2016;34(5):643-649.

\section{Publish your work in this journal}

OncoTargets and Therapy is an international, peer-reviewed, open access journal focusing on the pathological basis of all cancers, potential targets for therapy and treatment protocols employed to improve the management of cancer patients. The journal also focuses on the impact of management programs and new therapeutic agents and protocols on

\section{Dovepress}

patient perspectives such as quality of life, adherence and satisfaction. The manuscript management system is completely online and includes a very quick and fair peer-review system, which is all easy to use. Visit http://www.dovepress.com/testimonials.php to read real quotes from published authors. 